\title{
Youngest first? Why it is wrong to discriminate against the elderly in healthcare
}

\author{
C S Wareham, BA, MA, PhD \\ Steve Biko Centre for Bioethics, Faculty of Health Sciences, University of the Witwatersrand, Johannesburg, South Africa
}

Corresponding author: Christopher Wareham (christopher.wareham@wits.ac.za)

\begin{abstract}
In South Africa and abroad the elderly are systematically discriminated against at all levels of healthcare allocation decision-making. Such discrimination is perhaps surprising in light of the National Health Act and the Older Persons Act, which explicitly recognise the elderly as a vulnerable group whose equal rights require special protection. However, ethical theory and public opinion offer some reasons to think that discrimination against the elderly may be justified. This paper examines possible ethical grounds for age discrimination. I claim that there are very few cases in which the aged may be discriminated against, and that age alone is never sufficient grounds for discrimination.
\end{abstract}

SAfr J BL 2015;8(1):37-39. DOI:10.7196/SAJBL.374

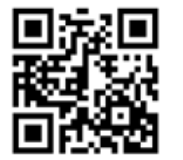

The South African (SA) Constitution is committed to the progressive realisation of the right to healthcare. ${ }^{[1]}$ However, in South Africa and abroad, it is not always possible for optimal medical treatment to be provided for every patient. This is due to resource scarcity: shortfalls in equipment, personnel, and funds make it impossible for every person to receive the treatment that would be best for them. ${ }^{[2]}$

Practitioners and policymakers alike are painfully aware that such shortfalls mean that allocation decisions will involve trade-offs, prioritising some patients or patient groups at the expense of others. But on what basis are such trade-offs made? What criteria should be used to decide who gets treatment and who does not? It is important that these criteria are explicit and ethically defensible as they affect who gets treatment and who does not, who lives and who dies.

It has become increasingly common for ethical theorists in the developed world to consider employing the criterion of age: where there is competition for health resources, the young should be favoured..$^{[2-6]}$ This type of discrimination can be employed at micro-, meso-, and macro-levels ${ }^{[]]}$of healthcare allocation. For instance, at the micro-level of individual practitioner decisions, it could mean that practitioners do not refer the elderly to more specialised secondary and tertiary levels of care. At the meso-level of hospital and practitioner policy, training for geriatric care may be deprioritised. At the macro-level of national or provincial health decisions, policies may favour the treatment of HIV/AIDS at the expense of geriatric medicine programmes because the former predominantly afflicts the young.

Significantly, age discrimination is already practised both tacitly and explicitly: all of the above are real examples from a South African health context and many more could be supplied. ${ }^{[8]}$ This is worrisome, not least since the elderly are a vulnerable population whose rights require special protection. ${ }^{[9]}$ The Older Persons Act explicitly states that the elderly are entitled to be respected, to be treated fairly and equitably, and to be protected against 'unfair discrimination on any ground.'[10] This means that it is vitally important to bring out potential justifications for age discrimination and question whether examples like those above involve unfairness.
Developed world bioethicists have debated these justifications extensively. However, bioethicists, healthcare practitioners, and legal experts in developing world contexts such as SA have been slower to comment on the ethical significance of age discrimination. In focusing on a SA context, this article contributes a different perspective to the broader debate about age-based rationing. However, the central contribution of the paper is to draw attention to highly questionable premises that underlie age discrimination, which nonetheless remain largely unquestioned in SA bioethics and health policy.

Many argue that there are good, principled reasons for favouring the young. In particular, it is sometimes suggested that the elderly provide a reduced social contribution, that the elderly have already had their fair share of life, and that they will benefit less from health resources. I will assess the criteria implicit in each of these claims, and the extent to which they apply to the elderly, and suggest that they fail to justify age discrimination.

\section{Social contribution}

It's sometimes thought that the degree to which individuals contribute to society should play a role in who gets medical resources. For instance, prioritising breadwinners is thought to be justified because they have many dependants who rely on them. ${ }^{[11]}$ The elderly on the other hand are often regarded as a burden on society. Older people extract a pension and after pensioning age may not contribute as much economically.

Interestingly, this type of consideration is reflected in one of the most prominent measures of the burden of disease: the Disability Adjusted Life Year (DALY) is endorsed by the World Health Organization and increasingly by health researchers and the South African government. The measure commonly 'weights' unhealthy middle years as contributing more to the burden of disease than unhealthy later years, since those in middle age are likely to provide a greater social and economic contribution.

However, the social contribution criterion, and the idea that the elderly contribute less are, respectively, morally and factually 
dubious. If social contribution is a relevant criterion, it requires discriminating in favour of those regarded as making greater economic, social and cultural contributions, such as presidents, politicians, celebrities, factory owners, and rich people who pay more tax. We would also be forced to discriminate against individuals who make smaller contributions, such as poor people, children, those without dependants or jobs, and the mentally ill. All of these provide a reduced contribution, but healthcare decisions that discriminate against these groups are rightly regarded as unacceptable.

The social contribution criterion therefore provides grounds for preferring people we don't think deserve preference, and for discriminating against groups who require the most social support. Such a criterion should be rejected. Even if we accepted it, however, it is false to claim that the elderly contribute less to society. A brief look at the pages of history will show many elderly figures who have made disproportionate social contributions. Nelson Mandela is a prime example of a person who contributed massively well beyond his $75^{\text {th }}$ year, but the contributions of elderly people are not limited to those who are famous. In SA, in particular, the aged are responsible for looking after families decimated by HIV/AIDS. ${ }^{[8]}$ They are also stores of cultural knowledge that have immense social value.

It might still be maintained that the elderly make a reduced economic contribution, since they draw from benefit schemes and do not earn a wage or pay taxes. However, this contention entirely ignores the lifetime contributions of the elderly, which surely incur an obligation of reciprocity. Moreover, it should be noticed that, to the extent that there is a reduction of economic contribution, this is in part due to the fact that the elderly are often forced to retire by mandatory retirement ages. It would be grossly unfair to prevent someone from working, and then deprive them of medical treatment because they no longer work.

The social contribution criterion is deeply problematic, as is the idea that the elderly provide a reduced social contribution. Discriminating against the elderly in resource allocation decisions cannot be justified on this basis.

\section{Fairness}

A further attempt at justifying age discrimination is provided by the idea of a fair innings. Some argue that one goal of health services should be to ensure that each person has the same opportunity for a fair number of healthy years: we should all get a fair opportunity to play the game of life for the same time. Williams ${ }^{[3]}$ suggests that, on this basis, it may sometimes be justified to discriminate against the elderly, since they have had a greater share of the good of life. The young should get healthcare resources, so as to give them a better opportunity for a 'complete life! ${ }^{[2]}$

The fair innings criterion is certainly more convincing than the social contribution criterion, and evidence suggests that many people endorse this reason for deprioritising the elderly. ${ }^{[12]}$ However, the fair innings view is also ethically questionable. Once again, employing the criterion would mean discriminating in favour of individuals we do not think should be preferred. For instance, fetuses have had only a fraction of their fair innings. Nonetheless, only the most zealous pro-lifer would think that we should save a fetus's life over that of its mother, who has had a greater share of her fair innings. It could be claimed that the preference for mothers in this case is due to the fact that the fetus is not a fully-fledged person. As a nonperson, perhaps its share of life should not figure substantially in our weighing-up. Although many reject the idea that the unborn embryo is not a person, accepting this controversial view might rescue the fair innings criterion from one counter-intuitive consequence.

There are, however, additional, less easily escapable criticisms of the fair innings view. The fair innings requirement might also condone extreme discrimination against the very old. If one lives 110 good years one has drastically exceeded one's quotient. Because the extreme elderly have already had much more than their fair share, the fair innings argument may recommend denying them any opportunity to access interventions even if they would benefit much more than a younger person. Similarly, even inexpensive care or treatments might be entirely denied to the elderly just because they have exhausted their fair share of resources. A criterion that recommends such neglect must be rejected.

Moreover, even if the fair innings criterion were accepted, being old is an unreliable indicator of fairness: it is often false to say that an older person has had his or her fair share of life's goods. Many older persons will have lived lives of deprivation, hardship and disability. This is particularly true in nations, such as SA, in which the vast majority of elderly people have been the victims of unjust deprivation and discrimination throughout their lives. Often elderly black persons who have lived through apartheid will not have had their fair share of life's goods. If applied correctly, then, the fair innings criterion may require favouring the elderly in nations such as our own.

The fair innings requirement seems to have a degree of appeal. Nonetheless it should once again be clear that the criterion is flawed. And even if it was not, it provides inadequate grounds for discriminating against the elderly, particularly in SA.

\section{Degree and likelihood of benefit}

The strongest basis for discriminating against the elderly is the principle that we should do the most good and provide the most benefit with the resources at our disposal. This common sense idea is related to the bioethical principle of beneficence and has a theoretical foundation in utilitarian ethical theory. ${ }^{[13]}$ On the face of it, it seems likely that more benefit will accrue by treating the young rather than the elderly. A person who receives a heart transplant at the age of 40 is likely to gain many more healthy life years than a person who receives a transplant at the age of 85 . The older person is likely to have poorer health and die from other causes before he or she can enjoy the full benefit of the intervention.

Despite its intuitive appeal, though, the benefit criterion has some unpalatable implications. If we accept it, we should discriminate against all groups with reduced life expectancy. Smokers and the overweight become obvious candidates to be deprioritised in health allocation decisions. Some find this consequence acceptable. Less easy to defend, though, is the implication that we should discriminate on grounds of race, class, or occupation. It is an unfortunate fact that certain races and classes live shorter lives. ${ }^{[14]}$ Similarly, those in dangerous professions such as soldiers, policemen, and miners are likely to have reduced life expectancy. The benefit requirement unacceptably provides grounds for health decisions to discriminate against these groups along with the elderly.

Nonetheless, as discussed earlier, we do need some method of 
making allocation decisions, and perhaps a refined benefit criterion is the best of a bad bunch. Even if we accepted a benefit requirement, though, this would not provide grounds for generalised discrimination against the elderly. This is because the range of treatments from which the elderly are less likely to benefit appears to be extremely limited. These include life-saving treatments with very long-term benefits, such as organ transplants and heart surgery. Moreover, even deciding that the elderly should not get these is questionable. There is huge variability in humans' age-relative health profiles, which gives rise to differences in expected healthy life years. This means that it would be far better to assess individual chances of benefit rather than generalise according to chronological age.

Once again, the benefit criterion is flawed. And once again, even its acceptance would not justify blanket discrimination against the elderly.

\section{An objection: the elderly are willing to take a back seat}

Before concluding, it is worthwhile to pre-empt a common objection to the claim of this paper. The objection is that the elderly themselves often wish for young people to be treated ahead of them. It is certainly true that the opinions and decisions of the elderly, with regard to their own care, must be respected. It is arguably wrong for a practitioner to supply care that any capable patient, old or young, does not want.

Even so, two responses should be made to this objection. First, it is highly likely that the elderly themselves may have internalised some of the above flawed arguments for discrimination. When an elderly person offers such arguments for favouring the young, there may be a moral obligation to try to make the person aware of the unsound basis of their preference.

The second response is that, like many of the arguments in favour of age discrimination, it rests on a claim that is no more applicable to the elderly than it is to others. While it is certainly true that some elderly people prefer that others should be helped first, this is also true of many younger altruistic people. Moreover, it is true of the elderly far less often than many people think. ${ }^{[15]}$ It is incorrect to assume that elderly people simply accept that they should fall further down the pecking order in resource allocation decisions. Policymakers and healthcare practitioners should not base discriminatory resource allocation decisions on this false assumption.
It is not just abuse of the elderly that is wrong. Although such abuse is abhorrent and must be remedied, it is important to note that the elderly are discriminated against in more subtle, passive, and systematic ways. The non-provision of interventions to which they are as ethically and legally entitled as younger people can be as damaging as active abuse. As it stands, the elderly are tacitly, explicitly, and systematically discriminated against at all levels of healthcare. Policymakers and healthcare practitioners have an ethical and legal obligation to ensure that the vulnerable elderly should not bear an unfair burden due to unjustified resource allocation decisions.

In case this obligation to others is not motivational enough, it is also worth pointing out that it is in each individual's interest to undermine unfair discrimination: we all grow old, so it makes sense to defend our rights before we become vulnerable to their violation.

Acknowledgements. This paper has benefitted from fruitful discussions with members of the Philosophy Department at the University of Johannesburg, as well as participants at the Philosophy Spring Colloquium 2014. Thanks also to the two anonymous reviewers for probing comments.

\section{References}

1. Republic of South Africa, Constitution of the Republic of South Africa. Government Gazette 1996.

2. PersadG, Wertheimer A, EmanuelEJ.Principles for allocation of scarce medical interventions. Lancet 2009;373(9661):423-431. [http://dx.doi.org/10.1016/S0140-6736 (09)60137-9]

3. Williams A. Intergenerational equity: an exploration of the 'fair innings' argument. Health Econ 1997;6(2):117-132.

4. Callahan D. Aging and the ends of medicine. Ann NY Acad Sci 1988;530(1):125-132.

5. Shaw A. In defence of ageism. J Med Ethics 1994;20(3):188-191.

6. Harris J. Does justice require that we be ageist? Bioethics 1994;8(1):74-83.

7. Dhai A, McQuoid-Mason DJ. Bioethics, Human Rights and Health Law: Principles and Practice. Cape Town: Juta 2010.

8. Chenwi L (Ed). Economic and social rights in South Africa. Special edition on the rights of older persons. ESR review 2011;12(1)

9. Republic of South Africa, National Health Act No. 61. Government Gazette 2003.

10. Republic of South Africa. Older Persons Act No. 13. Government Gazette 2006.

11. Murray CJL, Acharya AK. Understanding DALYs. J Health Econ 1997;16(6):703-730.

12. Dolan P, Tsuchiya A. It is the lifetime that matters: public preferences over maximising health and reducing inequalities in health. J Med Ethics 2012;38(9):571-573. [http://dx.doi.org/10.1136/medethics-2011-100228]

13. Beauchamp TL, Childress JF. Principles of Biomedical Ethics. Oxford: Oxford University Press, 2001.

14. Adler NE, Boyce WT, Chesney MA, Folkman S, Syme SL. Socioeconomic inequalities in health. No easy solution. JAMA 1993;269(24):3140-3145.

15. Zweibel NR, Cassel CK, Karrison T. Public attitudes about the use of chronological age as a criterion for allocating health care resources. Gerontologist 1993;33(1):74-80. 